\title{
Spontaneous Intestinal Perforation
}

National Cancer Institute

\section{Source}

National Cancer Institute. Spontaneous Intestinal Perforation. NCI Thesaurus. Code

C114910.

A focal intestinal perforation without a definite cause, commonly located in the terminal

ileum, lacking the transmural inflammation and/or pneumatosis typically seen in necrotizing enterocolitis. 